\title{
AVALIAÇÃO DO USO DE BENZODIAZEPÍNICOS ENTRE ESTUDANTES DO CURSO DE FARMÁCIA NO CENTRO UNIVERSITÁRIO PRESIDENTE ANTÔNIO CARLOS-BARBACENA- MG
}

\section{ARTIGO ORIGINAL}

BARBOSA, Dara Cezário ${ }^{1}$, ZINI, Cintia Elena Leite ${ }^{2}$

BARBOSA, Dara Cezário. ZINI, Cintia Elena Leite. Avaliação do uso de benzodiazepínicos entre estudantes do curso de farmácia no centro universitário presidente Antônio Carlos-Barbacena-MG. Revista Científica Multidisciplinar Núcleo do Conhecimento. Ano. 06, Ed. 11, Vol. 02, pp. 05-18. Novembro 2021. ISSN: 2448-0959, Link de acesso: https://www.nucleodoconhecimento.com.br/saude/uso-de-benzodiazepinicos, DOI: 10.32749/nucleodoconhecimento.com.br/saude/uso-de-benzodiazepinicos

\section{RESUMO}

Os benzodiazepínicos são utilizados como hipnóticos, sedativos, ansiolíticos, anticonvulsivantes e relaxantes musculares, estando entre os medicamentos mais prescritos e utilizados no mundo. $\mathrm{O}$ aumento progressivo do número de usuários é um ponto importante a ser discutido, visto que seu uso contínuo tem sido associado a síndromes de abstinência, dependência, tolerância e reações adversas, tornandose motivo de preocupação, principalmente no âmbito universitário. O presente artigo apresenta como problemática a hipótese de que o uso de benzodiazepínicos é frequente em estudantes universitários do curso de farmácia do Unipac Barbacena MG. Nesse contexto, o objetivo do presente trabalho foi conhecer o perfil de utilização destes medicamentos pelos estudantes de Farmácia do Unipac Barbacena - MG. Realizou-se a coleta de dados através de questionário online via Google

${ }^{1}$ Graduada em Farmácia. ORCID: https://orcid.org/0000-0003-2904-7526

${ }^{2}$ Orientadora.

RC: 100550

Disponível em: https://www.nucleodoconhecimento.com.br/saude/uso-debenzodiazepinicos 
Forms, disponibilizado no período de 22 de agosto a 30 de setembro de 2020 (Parecer CEP Unipac 4.212.688). Consideraram-se válidos 30 questionários respondidos, sendo a maioria mulheres na faixa etária entre 21 e 25 anos (57\%). Os benzodiazepínicos foram utilizados por $66,6 \%$ dos participantes, sendo o fármaco de maior frequência o clonazepam (41\%), seguido de diazepam (22\%) e alprazolam (19\%). Entre os motivos do uso, ressaltam-se ansiedade (44\%), depressão (18\%) e insônia (18\%). Dos estudantes que utilizaram benzodiazepínicos, $65 \%$ o fizeram por período maior que 6 meses, o que pode induzir dependência e síndrome de abstinência, contradizendo recomendações da bula e da literatura. Os dados revelam um uso significativo destes medicamentos pelos estudantes e o farmacêutico apresenta papel central no uso racional e podem motivar ações institucionais nesse sentido.

Palavras-chave: Benzodiazepinas, Estudantes, Uso racional de medicamentos.

\section{INTRODUÇÃO}

O intenso quadro de transformações decorrentes do último século levou ao surgimento excessivo de transtornos de ansiedade, depressão, entre outros. Dentro desse ambiente opressor, tem-se em destaque a graduação: período crítico e de maior vulnerabilidade dos estudantes, visto que, por se tratar de um ambiente que apresenta diversos fatores ansiogênicos, contribui para o desenvolvimento da ansiedade e outros quadros em que venha a ser necessário o uso de medicação. (MARCHI, 2013)

Entre as diversas drogas psicotrópicas com atuação sobre o sistema nervoso central (SNC) tem destaque a classe dos benzodiazepínicos (JUNIOR, 2014). mecanismo de ação dessa classe de medicamentos ocorre pela capacidade de se ligarem a um sítio regulador específico sobre o receptor ácido gama-aminobutírico (GABA). Em decorrência dessa ligação, há uma potencialização da ação neuro inibidora do GABA, o que leva a uma redução da excitabilidade celular. Logo, tem-se uma acentuação dos processos inibitórios no SNC, ocasionando, assim, um efeito 
depressor (CARLINI, 2001; RIBEIRO, 2017). Atuam como hipnóticos, sedativos, anticonvulsivantes e relaxantes musculares, e são principalmente utilizados no tratamento da ansiedade aguda e da insônia transitória (ZORZANELLI, 2019).

A meia vida longa, a possibilidade de vias de administração diversificadas e o elevado índice terapêutico contribuem para a ampla difusão dessa classe entre médicos e pacientes. Segundo relatórios de órgãos internacionais, como a OMS e o The International Narcotics Control Board (INCB), existem indícios do uso indiscriminado desses medicamentos e um controle insuficiente nos países em desenvolvimento, como o Brasil (MENDES, 2015).

A complexidade envolvida na utilização de tais medicamentos está correlacionada aos graves problemas que eles ocasionam, não havendo uma prevalência dos benefícios quando comparado às dificuldades que podem vir a surgir em um quadro de dependência proveniente do uso. A dependência dos benzodiazepínicos acarreta prejuízos à saúde do paciente, tanto no âmbito social quanto na qualidade de vida (JUNIOR, 2014). Essa classe também apresenta enorme potencial indutor de síndrome de abstinência e de reações adversas, como a sedação, depressão respiratória, alterações psicomotoras, disfunção cognitiva (ZORZANELLI, 2019; COMHUPES, 2013). É recomendado que o tratamento não ultrapasse um período de seis meses (JUNIOR, 2014).

O uso dos benzodiazepínicos por estudantes é uma realidade e pode ser influenciado por uma série de fatores, que incluem as circunstâncias socioculturais, ausência de programas informativos sobre automedicação, a facilidade de obtenção de receituários, principalmente por acadêmicos da área de saúde. Em junção a estes, os conhecimentos adquiridos nas 4 disciplinas curriculares também se mostram insuficientes para modificar a percepção em relação ao risco associado ao uso irracional dessas drogas (RIBEIRO, 2017).

O farmacêutico tem papel fundamental no que se refere à promoção do uso racional de medicamentos. Por meio da assistência e atenção farmacêutica, esse profissional 
pode proporcionar a população mais informações sobre o uso racional, o que garante uma maior segurança e eficácia durante a terapêutica, juntamente com uma minimização das reações adversas aos medicamentos (MARCHI, 2013; BARRETO, 2019).

O presente artigo apresenta como problemática a hipótese de que o uso de benzodiazepínicos faz parte da realidade dos estudantes universitários de farmácia da Unipac Barbacena - MG, devido ao contexto no qual estão inseridos, como a ansiedade gerada pela carga de estudos e a necessidade de se obter boas notas.

Partindo-se do contexto de uso irracional crescente de benzodiazepínicos, bem como da atuação do farmacêutico como profissional ativo na promoção ao uso racional de medicamentos, o presente trabalho objetivou conhecer o perfil de utilização de benzodiazepínicos pelos estudantes de Farmácia do Centro Universitário Presidente Antônio Carlos (Unipac) de Barbacena - MG e seus determinantes.

\section{DESENVOLVIMENTO}

Refere-se a um estudo de natureza descritiva e abordagem quantitativa tendo como população em estudo acadêmicos matriculados no curso de Farmácia do Centro Universitário Presidente Antônio Carlos (Unipac) de Barbacena-MG, no semestre 2020/2. O n amostral teórico foi constituído por 153 indivíduos, referente ao número de alunos matriculados no curso durante o $2^{\circ}$ semestre letivo de 2020. Os critérios de inclusão foram: estar regularmente matriculado no curso de Farmácia do Unipac Barbacena. Os critérios de exclusão foram: alunos que não preencheram completamente o questionário; alunos que se recusaram a participar da pesquisa; alunos que desistiram de responder o questionário após o início do mesmo. Aos participantes foi explicado os objetivos da pesquisa e esclarecido os princípios de confidencialidade, privacidade, anonimato e a garantia de que a não participação ou desistência a qualquer momento da pesquisa não acarretaria prejuízos e/ou constrangimentos. Após esclarecimentos, os participantes foram convidados a 
assinar um Termo de Consentimento Livre e Esclarecido. Os dados foram coletados mediante aplicação de um questionário semiestruturado (adaptado de acordo com as necessidades do estudo), elaborado com base no trabalho de Mendes (2015), contendo 13 perguntas, objetivas e discursivas, referentes à utilização de benzodiazepínicos. O questionário foi aplicado online, utilizando a ferramenta Google Forms, 5 disponível gratuitamente na plataforma Google aos alunos do curso de Farmácia, do Centro Universitário Presidente Antônio Carlos (Unipac) Barbacena/MG, com consentimento da Direção Acadêmica. O questionário ficou disponível para realização do dia 22 de agosto a 30 de setembro de 2020 . O projeto foi aprovado pelo Comitê de Ética e Pesquisa (CEP) envolvendo seres humanos do Unipac, CAAE:4.212.688. Os dados obtidos foram processados e analisados por meio da estatística descritiva (média, desvio padrão, frequência absoluta e relativa) utilizando-se o software Microsoft Office Excelß.

\section{RESULTADOS E DISCUSSÃO}

Dos 153 acadêmicos matriculados no $2^{0}$ semestre letivo de 2020 no curso de Farmácia do Unipac Barbacena, 34 responderam ao questionário. Desses, foram excluídos 4 participantes por não terem respondido ao questionário completamente. Foram considerados válidos 30 questionários. O Gráfico 1 apresenta a distribuição por período dos acadêmicos: 11 (36\%) correspondem a alunos do décimo período, 8 (27\%) do sexto, 7 (23\%) do oitavo, 2 (7\%) do terceiro e os outros $2(7 \%)$ ao segundo. Na amostra coletada, houve prevalência do sexo feminino 26 (87\%), com um predomínio de idade dos 21 aos 25 anos 17 (57\%). Entre 26 e 29 anos somaram-se 6 (20\%), entre 30 a 53 anos 7 (23\%), conforme demonstrado no Gráfico 2. Desses estudantes, $20(66,6 \%)$ já utilizaram benzodiazepínicos no decorrer de suas vidas. 
Gráfico 1: Distribuição por período dos acadêmicos do curso de Farmácia.



Fonte: Dados da Pesquisa (2020)

RC: 100550

Disponível em: https://www.nucleodoconhecimento.com.br/saude/uso-debenzodiazepinicos 
Gráfico 2: Faixa etária dos participantes.

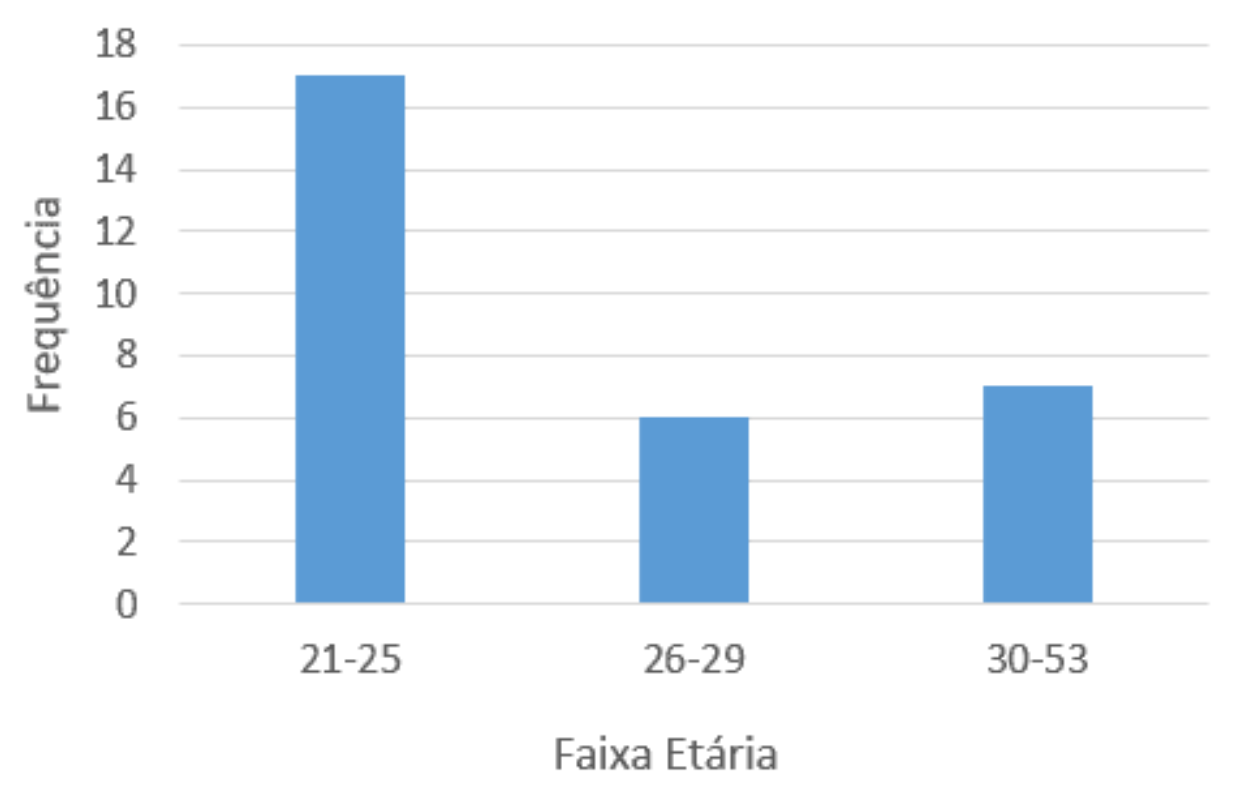

Fonte: Dados da Pesquisa (2020)

O predomínio do sexo feminino e das idades citadas anteriormente assemelham-se aos resultados de estudos realizados por Ribeiro (2017), com acadêmicos dos cursos de enfermagem e farmácia de uma faculdade particular do sudoeste da Bahia, que demonstraram um predomínio de mulheres $(66,7 \%$ e $51,1 \%$ ) entre faixa etária de 18 a 28 anos e 18 a mais de 30 anos, respectivamente, consumindo benzodiazepínicos.

O Gráfico 3 apresenta os agentes benzodiazepínicos mais utilizados pelos universitários de Farmácia, de acordo com a pesquisa. O Clonazepam foi o medicamento mais utilizado: 13 (41\%); seguido do Diazepam: 7 (22\%); Alprazolam: 6 (19\%); Bromazepam: 4 (12\%). Os menos utilizados foram o Lorazepam: $1(3 \%)$; e - Cloxazolam 1 (3\%). A ansiedade mostra-se como principal motivo para o uso destes medicamentos: 17 (44 \%); seguido da depressão: 7 (18\%); insônia: 7 (18\%); preocupação: 4 (10\%); outros motivos: $3(8 \%)$; e a dor: 1 (2\%). A elevada frequência de uso do clonazepam pelos acadêmicos (41\%), em comparação aos

RC: 100550

Disponível em: https://www.nucleodoconhecimento.com.br/saude/uso-de$\underline{\text { benzodiazepinicos }}$ 
demais medicamentos benzodiazepínicos, também foi observada nos estudos de Ribeiro (2017), houve predomínio do uso de clonazepam entre os acadêmicos de enfermagem $(33,3 \%)$ e farmácia $(40 \%)$, sendo a ansiedade um dos principais motivos de uso (26,7\% e $20 \%$ ). Segundo Botti (2010), também se observou um uso elevado desse medicamento pelos acadêmicos de enfermagem da PUC Minas, Campus Betim, sendo $42,8 \%$ entre mulheres e $50 \%$ entre homens.

Gráfico 3: Distribuição dos benzodiazepínicos utilizados pelos acadêmicos de Farmácia.

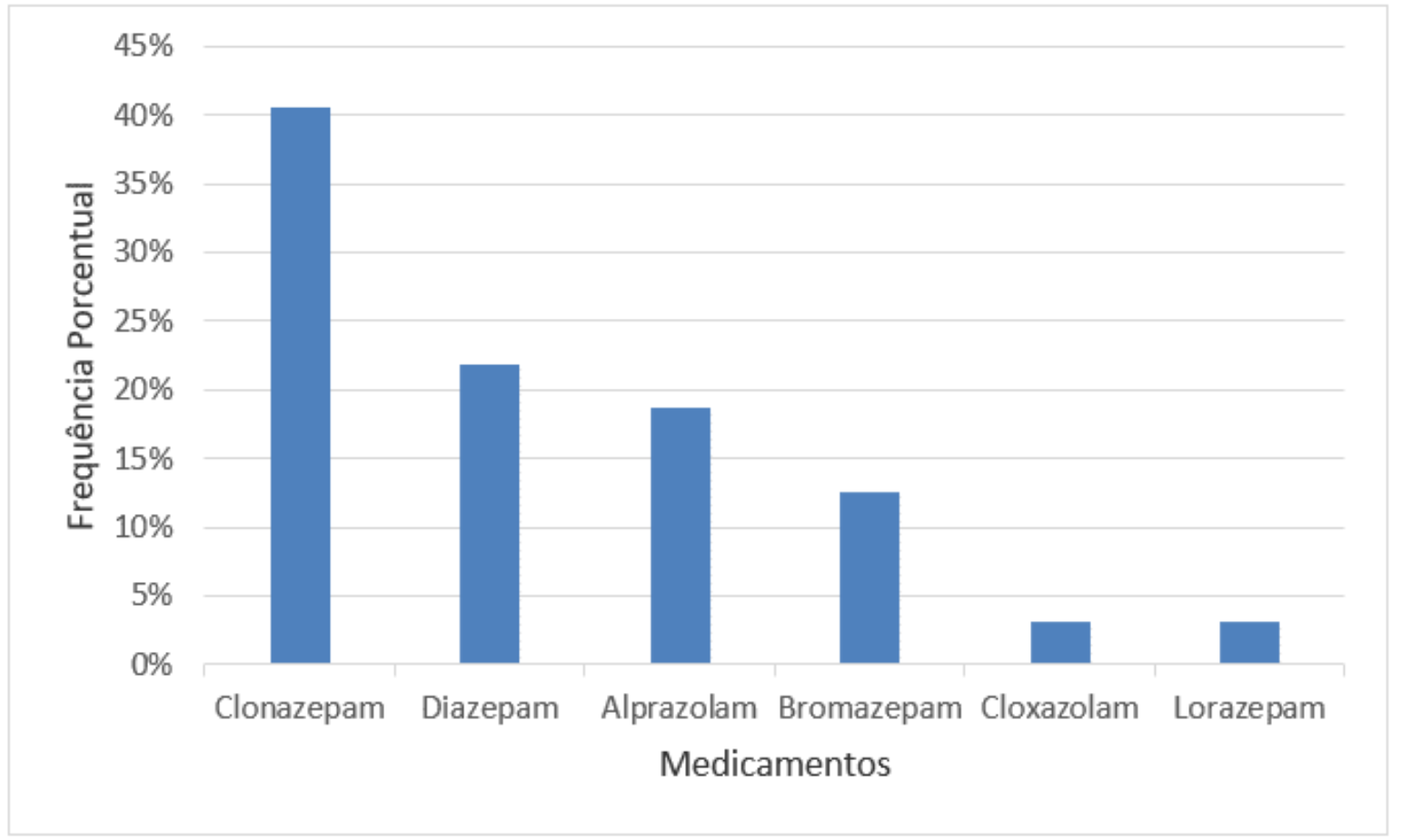

Fonte: Dados da Pesquisa (2020)

Dentre os estudantes que já utilizaram os medicamentos, 12 (60\%) acadêmicos relataram que passaram a fazer uso dessas drogas durante a faculdade. Os estudantes dos cursos de saúde demonstram níveis mais elevados de estresse e ansiedade pelo fato de estarem envolvidos com o cuidado ao paciente (RIBEIRO, 2017). Além disso, como a faculdade se trata de um ambiente ansiogênico, alguns fatores se mostram desencadeadores no que se refere ao desenvolvimento da ansiedade, como a insegurança, o medo de errar, de lidar com os pacientes, a

RC: 100550

Disponível em: https://www.nucleodoconhecimento.com.br/saude/uso-de$\underline{\text { benzodiazepinicos }}$ 
cobrança do desenvolvimento deles na prática acadêmica (MARCHI, 2013; MERRELL, 2008). Logo, movidos pela necessidade de adaptação à qual são impostos cotidianamente, passam a utilizar drogas psicotrópicas, em específico os benzodiazepínicos, com o intuito de obter uma minimização de suas adversidades psíquicas (MELINCAVAGE, 2011; PSICOLOTTO, 2010).

No Gráfico 4 pode-se observar o tempo de duração do tratamento relatado pelos acadêmicos. Desses, 7 (35\%) foram orientados a fazer a utilização dessas drogas por seis meses ou menos, estando de acordo com o que está descrito na literatura, que recomenda que o tratamento não ultrapasse um período de seis meses (JUNIOR, 2014).

Gráfico 4: Tempo de tratamento relatado pelos acadêmicos do curso de Farmácia.

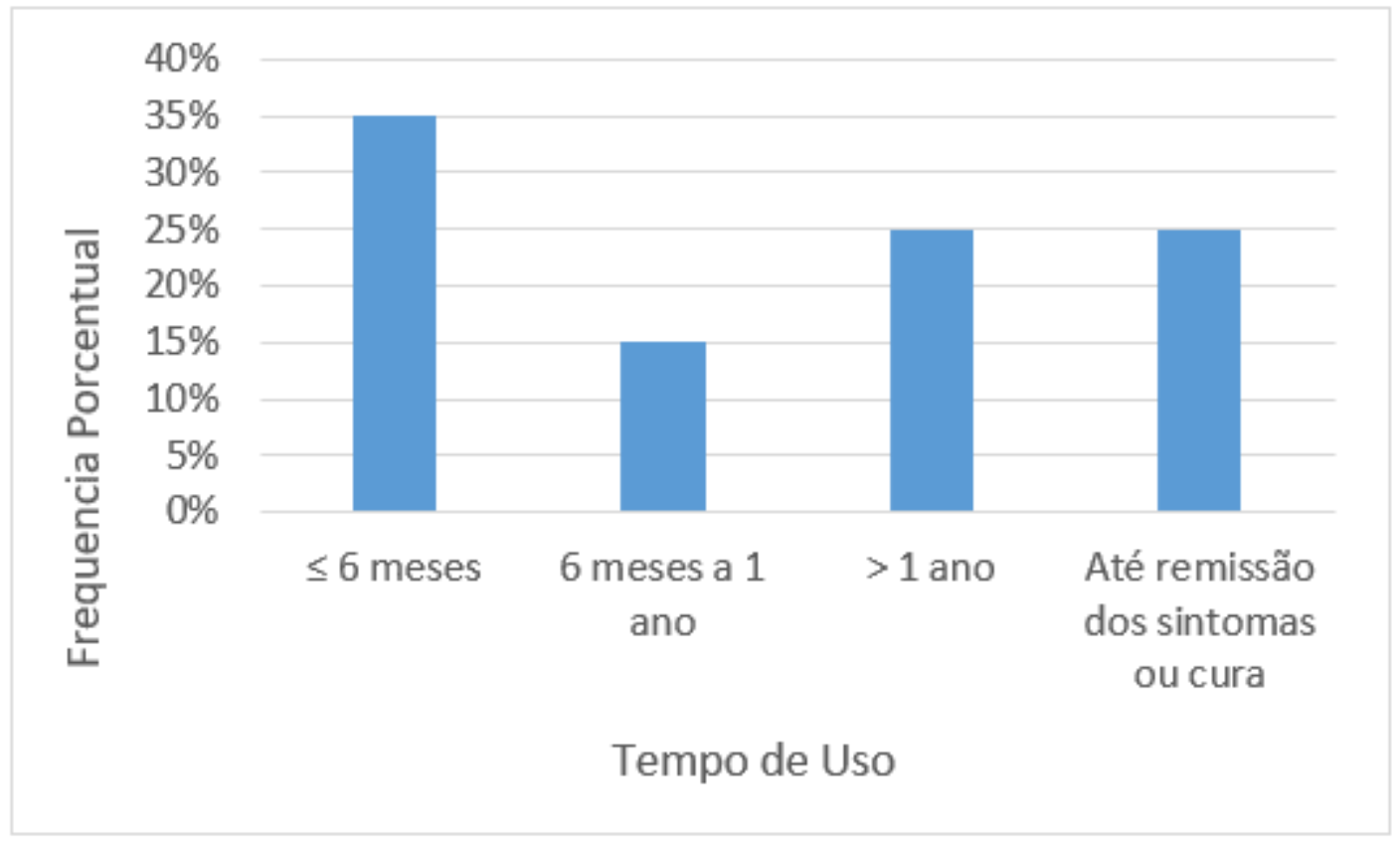

Fonte: Dados da Pesquisa (2020)

Ressalta-se que, conforme Gráfico 4, $13(65 \%)$ dos acadêmicos fazem o uso por tempo maior que o recomendado. Desses, $3(15 \%)$ fizeram uso por seis meses a um ano, $5(25 \%)$ por mais de um ano e $5(25 \%)$ até a remissão dos sintomas ou a cura. Esses dados também foram observados nos estudos realizado por Nordon (2009),

RC: 100550

Disponível em: https://www.nucleodoconhecimento.com.br/saude/uso-debenzodiazepinicos 
em que há uma predominância do tempo de utilização por período maior que o recomendado, de 12 a 35 meses $(15,2 \%)$ e mais de 36 meses $(69,6 \%)$. Tal fato torna-se motivo de preocupação em decorrência dos efeitos ocasionados pela utilização prolongada desses medicamentos, que incluem a dependência, abstinência e tolerância (ZORZANELLI, 2019). No que se refere à frequência de uso, $9(45 \%)$ fazem o uso diariamente, $6(30 \%)$ esporadicamente e $5(25 \%)$ somente em casos de emergência. Dos acadêmicos que fizeram o uso desses medicamentos, 9 (45\%) afirmaram ter apresentado algum efeito decorrente da utilização e 11 (55\%) não apresentaram nenhum. Constata-se ainda que a sonolência é o efeito colateral com maior preponderância entre os estudantes, $3(23 \%)$ conforme demonstrado no Graf. 5, estando de acordo com o estudo realizado por Ribeiro (2017), em que a sonolência excessiva foi o efeito colateral predominante entre os acadêmicos de Enfermagem $(73,3 \%)$ e Farmácia $(77,8 \%)$ que fizeram uso de benzodiazepínicos. De acordo com a literatura, os principais efeitos são: tontura e zumbidos, sonolência excessiva, falhas de memória, dependência e piora da coordenação motora (SANTOS, 2014; SILVA, 2014). 
Gráfico 5. Efeitos colaterais relatados pelos respondentes.

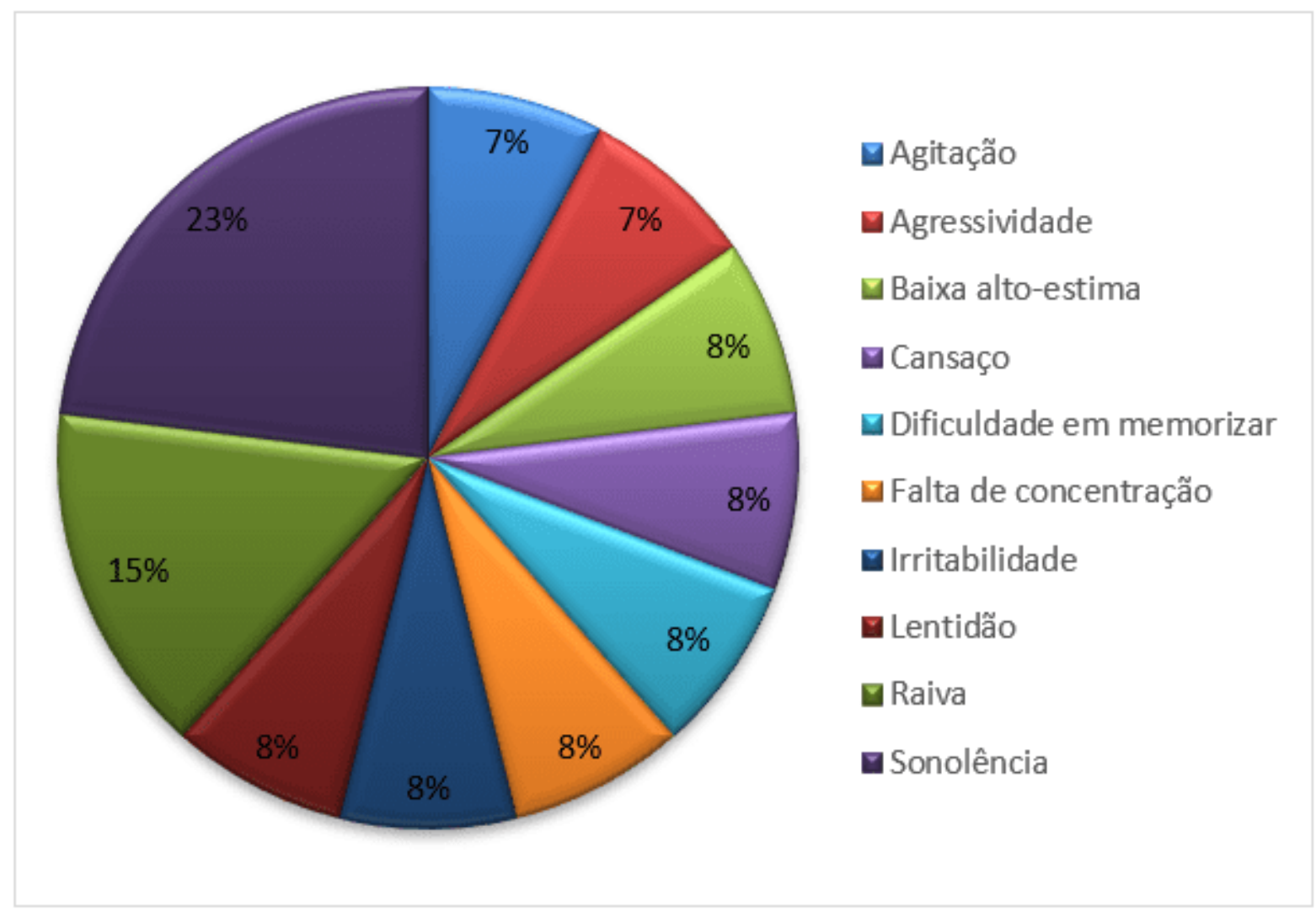

Fonte: Dados da Pesquisa (2020)

Em relação à influência dos conhecimentos adquiridos durante a graduação, 9 (35\%) disseram que o conhecimento os deixa mais confiantes, 4 (25\%) disseram que os conhecimentos adquiridos no curso os deixam parcialmente confiantes, o que contribui para aumento da confiança ao utilizarem esses medicamentos. $O$ aumento dessa confiança com o decorrer do curso está ligado ao estudo de conteúdos como a farmacocinética e a farmacodinâmica, presentes dentro de disciplinas da grade curricular, além do conhecimento mais aprofundado sobre os riscos, benefícios, interações e indicações dos medicamentos pelos acadêmicos de Farmácia (BARRETO, 2019).

No que se refere à prescrição, $16(80 \%)$ dos acadêmicos relataram que passaram a fazer uso dessas medicações por meio de indicação médica. Segundo estudo realizado por Mendes (2015) 90\% de médicos com diferentes especialidades 
afirmaram fazer a prescrição de psicofármacos. Observa-se que a indicação de benzodiazepínicos é um hábito que se encontra disseminado na rotina de prescrições médicas (MENDES, 2015). Várias pesquisas demostram que essa classe de medicamentos se encontra entre as substâncias prescritas com maior frequência e usadas regularmente por mais de $10 \%$ da população em inúmeros países (ALVES, 2016). Seu uso difundido entre médicos e pacientes está associado a diversas razões, como a meia-vida longa, diversidade de vias de administração, elevado índice terapêutico, possibilidade de metabólitos ativos. Além das características farmacológicas citadas, a popularidade entre os pacientes e o preço dessa classe também se mostram como condicionantes norteadores da prescrição (MENDES, 2015).

Durante o tratamento, 14 (70\%) dos acadêmicos afirmaram que tentaram interromper o uso do medicamento durante o tratamento e $6(30 \%)$ não tentaram. Desses, $4(20 \%)$ relataram que tiveram dificuldades com a interrupção e $3(15 \%)$ relataram uma dificuldade parcial. O Gráfico 6 apresenta as dificuldades que surgiram durante a interrupção forçada do tratamento, sendo a insônia o sintoma predominante: 4 (34\%); seguida da ansiedade: 2 (17\%); e dependência: $2(17 \%)$. Abstinência, agitação, alterações de humor e irritabilidade também foram relatadas, porém com menor frequência. Conforme estudo realizado por Nordon (2009), 91,3\% das mulheres que faziam o uso dos medicamentos e que buscavam tratamento na atenção primária tentaram realizar a interrupção e 60,9\% não obtiverem sucesso no processo, sendo a persistência dos sintomas anteriores ao uso, ansiedade e parestesias noturnas os principais motivos do insucesso.

RC: 100550

Disponível em: https://www.nucleodoconhecimento.com.br/saude/uso-debenzodiazepinicos 
Gráfico 6. Dificuldades relatadas na interrupção do tratamento pelos acadêmicos de Farmácia.

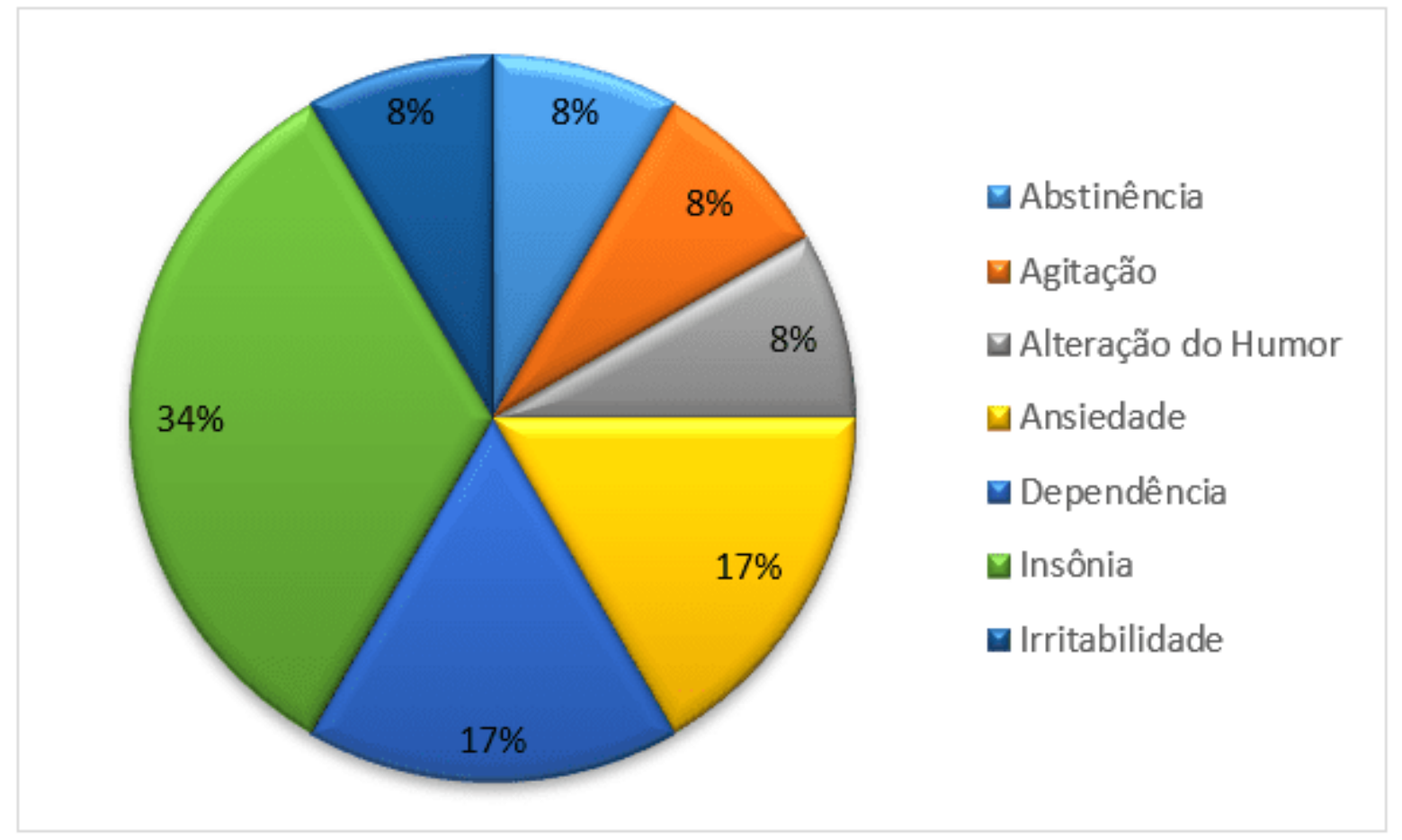

Fonte: Dados da Pesquisa (2020)

Salienta-se que a retirada deve ocorrer de forma lenta e gradual, devido ao surgimento frequente de sintomas severos provenientes da abstinência e do "efeito rebote", principalmente distúrbios associados ao sono. Além desses, outros problemas durante 0 processo de retirada podem surgir, como ansiedade, inquietação, letargia, sedação e incapacidade de realização de determinadas atividades diárias (JUNIOR, 2014; MANTOVANI, 2019). Em relação à permanência do efeito, 10 (50\%) dos acadêmicos afirmaram que não houve uma redução do efeito ao longo do tempo, 5 (25\%) afirmaram uma redução parcial do efeito e os outros $5(25 \%)$ relataram não haver perda do efeito. Segundo os resultados do estudo realizado por Mendes (2015) há uma prevalência da eficácia ao longo do tratamento $(68,57 \%)$ relatada pelos usuários, sendo a perda dessa eficácia a longo prazo inferior $(31,43 \%)$. Mas essa redução do efeito pode estar associada ao fenômeno da tolerância, que se desenvolve em decorrência do uso crônico do 
fármaco. No caso deles, ocorre uma mudança compensatória dos receptores dos benzodiazepínicos e do GABA, fazendo com que se tornem menos responsivos, o que desencadeia redução de suas ações inibitórias. Isso faz com que a dose inicial tenha menor efeito, havendo necessidade de uma dose mais elevada para se obter o efeito original (MENDES, 2015).

O farmacêutico como promotor ativo da saúde apresenta papel primordial sobre orientação ao uso desses medicamentos. Por meio do aconselhamento terapêutico, tem-se uma contribuição para seu uso racional, garantindo uma maior segurança e eficácia da terapêutica, redução de possíveis interações de medicamentos e minimização das reações adversas, que são comumente observadas durante o uso crônico dessas drogas e podem vir a se tornar um grave problema dentro do setor de saúde (MARCHI, 2013; BARRETO, 2008; ALVES, 2016).

\section{CONSIDERAÇÕES FINAIS}

O número de respondentes foi inferior ao esperado, o que se atribui à aplicação do formulário online, visto que não houve contato presencial para solicitação das respostas. Todavia, os resultados encontrados neste estudo demonstraram que o uso de benzodiazepínicos pelos estudantes de Farmácia do Unipac Barbacena-MG é expressivo, confirmando a hipótese inicial, composto em sua maioria por mulheres. As principais razões para utilização de benzodiazepínicos foram ansiedade, depressão e insônia e clonazepam e diazepam os medicamentos mais frequentemente utilizados. Observou-se uso por tempo maior que o recomendado, e uma maior confiança na utilização em virtude dos conhecimentos adquiridos durante o curso. Partindo-se do contexto da avaliação do perfil destes estudantes e dos determinantes envolvidos no uso de benzodiazepínicos, conclui-se que é pertinente a discussão do assunto bem como a implantação de ações na faculdade que estimulem o uso racional desses medicamentos. 


\section{REFERÊNCIAS}

ALVES, D. M. P.; COELHO, V. G. M. A.; KOHLER, L. M. Perfil de um grupo de usuários de clonazepam no município de Manhuaçu. REMAS. 2016; 6(1):43-60.

BARRETO, K. M. S. Automedicação em estudantes de graduação em farmácia: uma revisão narrativa. [monografia]. Sergipe: Universidade Federal do Sergipe; 2019.

BOTTI, N. C. L.; LIMA, A. F. D.; SIMÕES, W. M. B. Uso de substâncias psicoativas entre acadêmicos de enfermagem da Universidade Católica de Minas Gerais. Rev Eletrônica Saúde Mental Álcool Drog. (Ed. port.) [online]. 2010; 6(1): 1-16.

CARLINI, E. A.; NAPPO, A. S.; GALDURÓZ, J. C. F.; NOTO, A. R. Drogas psicotrópicas: o que são e como agem. Revista IMESC. 2001; 3: 9-35.

COMPLEXO HOSPITALAR UNIVERSITÁRIO PROFESSOR EDGARD SANTOS (COMHUPES). Benzodiazepínicos: Características, Indicações, Vantagens e Desvantagens. Diretrizes Clínicas de abril de 2013 [acesso em 2020 fev 27]. Disponível em:http://www2.ebserh.gov.br/documents/1975526/2520527/Diretriz_27_Benzodiaze pinicos_caracteristicas_indicacoes_vantagens_e_desvantagens.pdf/8d736590-40fe4d67-9b7e32f8fd3aae69

JUNIOR, Z. A. M.; CAPONI, S. N. C. Condicionantes relacionados ao uso crônico de clonazepam no Brasil: uma história de vida. Cad. de Pesq. Interdisc. em Ci-s. Hum-s. 2014; 15(106):117-139.

MANTOVANI, C. M. L.; QUAGLIATO, F. F. Uso abusivo de benzodiazepínicos: o processo de desprescrição. Rev Fac Ciênc Méd Sorocaba. 2019;21(3):147-8.

MARCHI, K. C.; BÁRBARO, A. M.; MIASSO, A. I.; TIRAPELLI, C. R. Ansiedade e consumo de ansiolíticos entre estudantes de enfermagem de uma universidade pública. Rev. eletrônica enferm. 2013; 15(3): 729-37. 
MELINCAVAGE, S. M. Student nurses' experiences of anxiety in the clinical setting. Nurse Educ Today. 2011; 31:785-789.

MENDES, C. M. M. Estudo farmacoepidemiológico de uso e prescrição de benzodiazepínicos em Teresina. [tese]. Fortaleza: Universidade Federal do Ceará; 2015.

MERRELL, K. W. Helping Students overcome depression and anxiety: a pratical guide. 2 ed. Nova lorque: Guilford press; 2008.

NORDON, D. G.; AKAMINE, K.; NOVO, N. F.; HÜBNER, C. K. Características do uso de benzodiazepínicos por mulheres que buscavam tratamento na atenção primária. Rev. psiquiatr. Rio Gd. Sul. 2009; 31(3): 152-158.

PICOLOTTO, E.; LIBARDONI, L. F. C.; MIGOTT, A. M. B.; GEIB, L. T. C. Prevalence and factor associated with psychoactives substances consumption for academics of Nursing of the University of Passo Fundo. Ciên saúde colet. 2010; 15(3): 645-654.

RIBEIRO, B. S.; RODRIGUES, R. L. A.; DUARTE, S. F. P. Prevalência e Fatores Associados com o Consumo de Benzodiazepínicos por Acadêmicos de Enfermagem e Farmácia de uma Faculdade Particular do Sudoeste da Bahia. Rev Mul e de Psico. 2017, 38(11): 166- 176.

SANTOS, C. A. G. Descontinuação do uso indiscriminado de benzodiazepínicos entre os usuários da UBS Rasa em Ponte Nova [monografia]. Ponte Nova: Faculdade de Medicina, Núcleo de Educação em Saúde Coletiva - UFMG; 2014.

SILVA, M. L.; REGO, F. S.; ROQUE, N. F.; VALENTI, V. E. Use of psychoactive substances in students at a public university. ABCS Health Sci. 2014; 39(3):160166.

RC: 100550

Disponível em: https://www.nucleodoconhecimento.com.br/saude/uso-debenzodiazepinicos 
ZORZANELLI, R. T. et al. Consumo do benzodiazepínico clonazepam (Rivotril(囚) no estado do Rio de Janeiro, Brasil, 2009-2013: estudo ecológico. Ciênc. Saúde Colet. 2019; 24(8): 3129-40.

Enviado: Outubro, 2021.

Aprovado: Novembro, 2021. 